\title{
Interactive comment on "Characterization of Canadian High Arctic glacier surface albedo from MODIS C6 data, 2001-2016" by Colleen A. Mortimer and Martin Sharp
}

Colleen A. Mortimer and Martin Sharp

cmortime@ualberta.ca

Received and published: 14 November 2017

The comment was uploaded in the form of a supplement:

https://www.the-cryosphere-discuss.net/tc-2017-160/tc-2017-160-AC1-

supplement.pdf 